\title{
Conjurar a qualificação de violência: justificativas e práticas do recurso à coerção nas hospitalizações psiquiátricas
}

(Conjurer la qualification de violence: justifications et pratiques du recours a la contrainte lors des hospitalisations psychiatriques)

(Conjuring up the qualification of violence: justifications and practices of the resource of coercion in psychiatric hospitalizations)

(Conjurar la calificación de violencia: justificaciones y prácticas del recurso a la coacción en las hospitalizaciones psiquiátricas)

Delphine Moreau*

\begin{abstract}
Resumo
As hospitalizações sem consentimento estão no centro da acusação contra a Psiquiatria, por esta exercer coerções ilegítimas. Essa crítica é feita pelos próprios profissionais da área. Com cerca de 13\% de hospitalizações em duas modalidades definidas pela Lei 90-527, de 27/06/1990 - a hospitalização de ofício e aquela resultante da demanda de um terceiro -, o exercício da coerção é parte integrante do tratamento psiquiátrico e pode incluir reclusão em quartos de isolamento, tratamentos e outras coerções relativas às condições de hospitalização (vestimentas, visitas, recomendaçóes, etc.). A partir de entrevistas com diferentes categorias de profissionais (médicos, enfermeiros e técnicos) e de observações etnográficas nos serviços de urgência psiquiátrica e num serviço de hospitalização, analisamos, por meio de uma abordagem compreensiva, a maneira pela qual os profissionais justificam o uso da coerção e definem seus limites, de maneira a afastar a qualificação de violência.
\end{abstract}

Palavras-chave: hospitalização psiquiátrica; coerções; justificativas.

\section{Résumé}

Les hospitalisations sans consentement n'ont cessé d'être au cour de l'accusation portée contre la psychiatrie d'exercer des contraintes illégitimes, critique menée parfois par les professionnels eux-mêmes. Avec près de $13 \%$ des hospitalisations réalisées sous l'une des deux modalités définies par la loi du 27 juin 1990, l'hospitalisation d'office et à la demande d'un tiers, l'exercice de la contrainte est partie prenante du

Pesquisadora da École de Hautes Études em Sciences Sociales - EHESS, IMM-GSPM. E-mail: delphmoreau@free.fr. 
soin psychiatrique, et peut inclure placement en chambre d'isolement, administration de traitements, et autres contraintes concernant les conditions de l'hospitalisation (vêtements, visites, appels, etc.). A partir d'entretiens avec les différentes catégories de soignants (médecins, infirmiers et aides-soignants) et d'observations ethnographiques menées dans des services d'urgence psychiatrique et dans un service d'hospitalisation, nous avons analysé dans une approche compréhensive la manière dont les professionnels justifient le recours à la contrainte et en définissent les limites de façon à écarter la qualification de violence.

Mots-clé: hospitalisaion psychiatrique; contraintes; justifications.

\section{Abstract}

Hospitalization without consent is in the core of accusations against Psychiatry as it exerts illegitimate coercions, a criticism often expressed by professionals in the area themselves. With around 13\% of the hospitalizations carried out in two modes defined by the Law dated June 27, 1990 - office hospitalization and that resulting from a third party's demand - the exercise of coercion is an integral part of psychiatric treatment and may include reclusion in isolation rooms, administration of treatments and other coercions related to hospitalization conditions (clothing, visits, recommendations, etc.). Based on interviews with various categories of professionals (doctors, nurses and technicians), as well as on ethnographic observations in psychiatric urgency services and in one hospitalization service, we analyzed, by means of a comprehensive approach, the way professionals justify the use of coercion and define its limits, so as to evade the qualification of violence.

Key words: psychiatric hospitalization; coercions; justifications.

\section{Resumen}

Las hospitalizaciones sin consentimiento están en el centro de las acusaciones contra la Psiquiatría, ya que esta ejerce coacciones ilegítimas, crítica que a veces hacen los propios profesionales del área. Cerca del $13 \%$ de las hospitalizaciones se realizan en dos modalidades definidas por la ley de 27 de junio de 1990 - la hospitalización de oficio y la que resulta de la demanda de un tercero -, el ejercicio de la coacción forma parte del tratamiento y puede incluir la reclusión en cuartos de aislamiento, administración de tratamientos y otras coacciones relativas a las condiciones de hospitalización (vestiduras, visitas, recomendaciones, etc.). Basándonos en entrevistas a diferentes categorías de profesionales (médicos, enfermeros y técnicos) y de observaciones etnográficas en los servicios de urgencia psiquiátrica y en un servicio de hospitalización, analizamos, a través de un abordaje comprensivo, como los profesionales 
justifican el uso de la coacción y definen sus límites para que no llegue a ser clasificada como una violencia.

Palabras-clave: hospitalización psiquiátrica; coacciones; justificaciones.

\section{Introdução}

A internação forçada está sempre no cerne da crítica feita à Psiquiatria, crítica às vezes oriunda dos próprios profissionais. O "manicômio", na condição de lugar fechado de poder, no qual são possíveis todos os maus-tratos, às vezes disfarçados de "cuidados", foi denunciado com um vigor renovado depois da Segunda Guerra Mundial. Ora, as internações forçadas são e permanecem sendo parte integrante das práticas psiquiátricas: elas ocorrem em cerca de $13 \%{ }^{1}$ das internações ${ }^{2}$ e podem incluir, qualquer que seja a modalidade de internação, a colocação do paciente em quarto fechado, administração de tratamentos e outras restrições relativas às condições de internação (roupas, visitas, telefonemas, etc.). Além disso, os textos oficiais tendiam, pelo menos até recentemente, a atribuir somente uma função de cuidado (terapêutico) à Psiquiatria. A Lei de 14 de março de 2002 aperfeiçoou a evolução já presente na Lei de 27 de junho de $1990^{3}$, impondo, como condição à própria internação de ofício, a necessidade do cuidado: no art. 19, na décima alínea do artigo L 3212-9, as palavras "poderia comprometer a ordem pública ou a segurança das pessoas" foram substituídas pelas palavras: "cuidados em razão de distúrbios mentais que comprometam a segurança das pessoas ou atingem, de maneira grave, a ordem pública". A Circular Veil, n 48DG/SP3, de 19/jun/1993, relativa ao acolhimento e modalidades de internação de pacientes com problemas mentais, lembrava que, para as pessoas internadas sem o próprio consentimento, o artigo L 326-3 do Código de Saúde Pública define as coerçôes que podem ser aplicadas ao exercício de suas liberdades individuais, limitando-as "àquelas requeridas por seu estado de saúde e para a aplicação de seu tratamento". Isso ocorreu antes que os discursos do atual presidente da República, que era ministro do Interior, abordassem o tratamento psiquiátrico somente pela questão das internações de ofício e das diferentes medidas de segurança que ele preconiza, para as quais disponibiliza grandes recursos financeiros: quartos de isolamento, câmeras de vigilância, barreiras, braceletes eletrônicos,

\footnotetext{
Circular DGS/6C Nº 2004/237 de 24 de maio de 2004.

2 A lei de 27 de junho de 1990 as denomina "sem consentimento", e define dois modos: internação de ofício e a que resulta de requerimento de terceiro (NT: o texto e suas discussões se referem às leis francesas).

3 Esta lei francesa se refere aos direitos e à proteção das pessoas hospitalizadas por causa de problemas mentais, bem como às suas condiçôes de hospitalização. (N.T.)
} 
etc. ${ }^{4}$ Ora, ao serem reveladas as práticas das instituições psiquiátricas, a modalidade da relação médico-paciente sofreu um grande golpe, desde os trabalhos da sociologia interacionista, nos anos 1960: em Asiles, Goffman (1979) suspende não só a interpretação patológica das condutas dos "reclusos" em suas descrições, mas também a interpretação terapêutica das condutas das equipes médicas e de "cuidadores". Ele analisa as práticas dos profissionais da instituição como técnicas de poder, destinadas a fazer com que o novo recluso integre sua nova condição, seu novo status, com as diversas técnicas de despersonalização, de humilhação, da perda do que faz uma pessoa ser um "semelhante", em sociedade, bem como a imposição de diferentes imperativos que dizem mais respeito à organização da instituição e ao conforto da equipe, do que ao objetivo de saúde individualizado para a pessoa internada. Ora, se podemos relatar as condutas dos profissionais sem recorrer à sua justificativa de cuidados, não seria porque essa justificativa se revela ser perfeitamente vã? Mas será que Goffman (1979) relataria essas práticas de maneira "completa"? E até onde suas análises ainda seriam válidas hoje? Como anda a internação forçada hoje? Essa descrição, talvez necessária durante algum tempo, como diz Castel (1986), para romper o monopólio de descrição das práticas psiquiátricas feitas pelos próprios psiquiatras, certamente não esgota o sentido dessas práticas.

Analisaremos aqui a maneira pela qual os profissionais relatam a prática dessa internação forçada e definem seus limites, tentando afastar a qualificação de violência, presente especialmente na internação considerada ilegítima. Sem nos contentarmos com a hipótese do controle social, nem reduzirmos a interpretação do discurso dos cuidadores a uma justificativa a posteriori ("ideologias justificadoras" ou "reinterpretaçôes", como Goffman as chama, em Asiles), pretendemos tomar os objetivos de cuidado como cuidado terapêutico (cura) e como atenção à pessoa, o que inclui tarefas visando ao seu bem-estar (care), administradas pelos cuidadores. Pretendemos também analisar de que maneira a internação forçada está articulada nesse contexto. No entanto, não se trata de darmos apenas uma interpretação terapêutica da internação forçada, de modo a questionar seu sentido e sua legitimidade. Outros desafios emergem igualmente. Assim, seremos levados a repensar a antecipação e a gestão dos atos agressivos, bem como a regulação das tensões e das forças, dentro de um espaço coletivo. A análise da mobilização dos diferentes motivos e de sua articulação mostrará as tensões presentes no uso da internação forçada, em um contexto de cuidado.

\footnotetext{
Cf. Circular no DHOS/02/F2/2009/23 de 22 de janeiro de 2009. Esta lembra os princípios relativos ao acolhimento e às modalidades de estada dos pacientes internados por problemas mentais
} 
Essa análise é centrada na observação etnográfica, feita ao longo de seis meses, em um serviço de internação, completada por entrevistas com os psiquiatras, enfermeiros e auxiliares desse serviço. Aqui nos interessamos tanto pelos valores de referência dos cuidadores e pelos termos usados para designar a internação forçada quanto pelos dispositivos práticos aplicados de maneira a enquadrar o uso da força e o sentido de sua intervenção. As situações que eles julgam problemáticas foram analisadas como momentos críticos, em que a fronteira do "bom cuidado" é reafirmada ou redefinida.

Vamos, em um primeiro momento, voltar a falar sobre as noções de internação forçada e de violência antes de propor uma caracterização do quadro ideológico legitimado no serviço observado. Em seguida, apresentaremos a maneira pela qual esse serviço de internação relata sua reticência à internação forçada, em geral, e ao uso do quarto fechado, em particular. Distinguiremos, analiticamente, três usos principais do quarto fechado: terapêutico, de segurança e de ordem, antes de mostrar sua inserção na maneira pela qual os cuidadores se referem a ele, a fim de enfatizar os motivos mais legítimos.

\section{Retorno às noções de internação forçada e de violência em contexto psiquiátrico}

A internação forçada pode designar uma imposição administrativa, uma decisão de internação sem consentimento, legalmente enquadrada, autorizando limitações à liberdade de ir e vir ou coações práticas, referentes a dispositivos materiais e organizacionais (como fechar à chave o acesso ao serviço) ou a decisões dos médicos a respeito de situações individuais (por exemplo, a limitação dos telefonemas e das visitas autorizadas). Ela pode incluir um recurso efetivo à força, à dominação do corpo manu militari, visando à internação sem consentimento, à colocação do paciente em quarto fechado ou à administração de tratamento injetável. Isso supõe diferentes níveis simbólicos. Aristóteles (1990), ao examinar a distinção da ação voluntária e involuntária, em sua Ética a Nicômaco, não distingue a ação feita "pela força" daquela feita "sob o efeito da violência", que são designadas pela mesma palavra: Bià. No entanto, ele identifica essa zona ambígua das ações feitas sob ameaça. Esses níveis simbólicos estão nas diferentes formas de injunções, em referência à autoridade do saber psiquiátrico, à relação médico-paciente, já estabelecida em tratamento anterior. Assim, o paciente que não quer romper uma boa relação estabelecida antes dificilmente não se submeterá ao que seu médico lhe prescreve. No contexto da Psiquiatria pública, no entanto, é difícil escolher um médico, portanto também é difícil trocar de médico, 
apesar de esse direito ter sido reconhecido desde a Lei 90-527, de 27 de junho de 1990, como reza o Código de Saúde Pública, artigo L 3211.1. Ajuntem-se as pressões afetivas dos parentes, as pressōes "leves" mescladas ao exercício da força (não necessariamente bruta), as formas de ameaça, com a presença efetiva de enfermeiros ou de policiais, que não intervêm diretamente, a ameaça de hospitalização sem consentimento se o paciente não adere a uma internação livre, etc. (Lovell, 1996). Em trabalhos anteriores, analisamos algumas intervenções, situadas entre acompanhamento e coação, do ponto de vista das pessoas próximas a sujeitos que sofrem de distúrbios psiquiátricos (Moreau, 2007). O exercício da coação não implica necessariamente o uso da força e não exclui a busca de consentimento por parte dos cuidadores; ela coexiste, às vezes, até mesmo com o consentimento ou com a demanda dessa coação pelos pacientes. Há uma zona cinzenta entre o voluntário e o involuntário, e é por isso que analisaremos aqui esse momento em que a coação se objetiva em um ato "claro", como a colocação em quarto fechado. Lembremos que a colocação em quarto fechado não é reservada aos pacientes internados à força, mas pode ser aplicada em pacientes livremente internados.

A coação representada pelo quarto fechado não é administrativa. Do ponto de vista legal, ela está prevista no artigo L 326-3 do código de Saúde Pública, que limita as restriçôes ao exercício das liberdades individuais das pessoas internadas sem seu consentimento, mas só aquelas "requeridas por seu estado de saúde...”, como já citado na Circular Veil de 1993. Essa coação depende de prescrição médica. E só pode ser aplicada, segundo a circular Veil, aos pacientes internados sem consentimento ou, excepcionalmente, em caso de urgência, enquanto se aguarda a mudança da modalidade de hospitalização para as pessoas em internação livre, cujo único motivo de restrição à liberdade de ir e vir só pode ser "o bom funcionamento do serviço". As modalidades peculiares desse serviço devem ser precisadas no regulamento interno, sem que o princípio de respeito a essa liberdade de ir e vir possa ser questionado.

Trata-se, portanto, de uma restrição prática, decidida por um médico, por uma pessoa particular. $\mathrm{O}$ médico pode avalizar uma decisão dos cuidadores de colocação em quarto fechado. A interpretação corrente, legal e legítima, é de que ela deve ser um ato terapêutico. Um relatório da Agence Nationale d'Accréditation et d'Evaluation en Santé (ANAES) discute o uso do jargão "isolamento terapêutico" (Agence Nationale d'Accréditation et d'Evaluation en Santé, 1998; Senon \& Jonas, 2004).

Hoje a noção de violência é um conceito normativo e sempre negativo em contexto de cuidados à saúde. Assim, quando ela qualifica os atos de um "cuidador", vale como uma acusação. Em determinado sentido, qualquer 
coerção pode ser qualificada de "violenta" pelo fato de desviar e forçar o curso da conduta de uma pessoa, tal como ela mesma o determinaria. No contexto da Psiquiatria, em que as diferentes formas de constrangimento são integradas à prática comum legítima, a qualificação de "violento" pode designar três tipos de fatos. Pode-se, assim, designar (1) o recurso efetivo à força, de maneira dolorosa ou mediante troca de agressóes físicas; (2) em um sentido mais metafórico, mas de uso comum (lembremos a noção de "violência simbólica", em Bourdieu (1970), nas formas de humilhação ou de tratamentos morais julgados nefastos); (3) o constrangimento ilegitimo. Parecenos importante distinguir esses três níveis para evitar uma assimilação crítica que não permitiria analisar as situações.

Para o primeiro tipo, diferentes dispositivos e práticas têm o objetivo de evitar a brutalidade e as agressões físicas: negociações (chegando até a chantagens mais ou menos disfarçadas), instauração inicial de uma relação de forças manifestamente desigual, mas dosada. Isso pode se traduzir pela presença, um pouco recuada, de vários enfermeiros. De maneira geral, a regra é de "nunca ir sozinho a um quarto de isolamento". Não se trata de impor uma ameaça suscetível de se passar ao ato violento, em vez de apenas dissuadila. O objetivo desses dispositivos é evitar machucar o paciente, o que seria, por si só, considerado um erro, mas também evitar que o "cuidador" seja agredido por ele ou se machuque, em caso de uma interação física, uma luta corpo a corpo. De maneira geral, os cuidadores ficam prevenidos com relação a situaçóes em que existe um risco do corpo a corpo.

Para o segundo tipo, qualquer humilhação seria considerada como um mau cuidado - os cuidadores não consideram que o uso do quarto fechado constitui, por si só, uma humilhação. Veremos quais são as restrições consideradas como tratamentos morais nefastos.

No entanto a questão das fronteiras da restrição legítima é que estará no cerne deste texto - pois qualquer uso ilegítimo da restrição fará com que ela seja considerada uma violência ao mesmo tempo material e simbólica.

\section{Elementos de descrição do serviço: disposições organizacionais do serviço e referências teóricas, éticas e políticas do serviço}

O serviço que foi objeto da observação principal foi o de internação de um setor urbano, situado em vários distritos urbanos, cuja população gira em torno de 75 mil habitantes. Ele não está inserido dentro de um hospital imenso, como o que Goffman havia observado (um hospital federal com capacidade para até 8000 pessoas), mas faz parte de unidades que foram 
"relocalizadas" para perto das populações atendidas, desde o fechamento do antigo manicômio regional que acolhia essas unidades anteriormente. Essa mudança, que foi realizada no final dos anos 1990, foi desejada e apoiada pelo chefe do serviço, ativo defensor da Psiquiatria de setor (ver acima), e preparada com a equipe.

O serviço conta com 20 leitos para internação e funciona junto ao serviço de internação de outro setor, que também conta com 20 leitos. Ele está situado no nível do jardim, ou seja, um andar abaixo da recepção. Ele é "fechado", no sentido usual do termo em Psiquiatria, ou seja, o acesso a ele só se dá através de uma porta trancada, na qual o visitante tem que bater, ou por elevadores que também só podem ser abertos com chave. Os pacientes em internação livre devem, portanto, pedir passagem a um cuidador quando querem sair do serviço, por exemplo, para terem acesso à máquina de café no andar de cima. As portas que dão acesso ao jardim geralmente não ficam trancadas, exceto quando o serviço é decretado "fechado", o que acontece quando a equipe teme que algum paciente "fuja", ou seja, que ele escape do serviço, mas quer que ele possa deambular pelos corredores, e não deixá-lo trancado em seu quarto. De maneira geral, em Psiquiatria, fala-se de "serviço fechado" desde o momento em que o acesso ao serviço fica limitado por uma porta fechada à chave. Aqui, "fechado" designa um nível a mais de fechamento, uma grade pouco elevada nos fundos do jardim, o que oferece uma possibilidade de "fuga" aos pacientes em melhor forma física. Geralmente o serviço não fica fechado por muito tempo nesse sentido, pois as limitaçóes às deambulações dos pacientes, bem como à possibilidade de ir facilmente fumar um cigarro, tanto para os cuidadores quanto para os pacientes, são consideradas restritivas demais para o conjunto dos pacientes e para a equipe. Todos acham que elas fazem aumentar a tensão no serviço. Há sete quartos com dois leitos e seis quartos com um leito. Todos os quartos individuais podem ser fechados à chave. Entre esses, dois são arranjados para isso, o "quarto de isolamento" (de onde podem ser retirados todos os móveis, ficando somente um colchão ignífugo) e o "quarto de cuidados intensivos" (com os mesmos móveis que os outros quartos, mas fixados no chão). Esses dois quartos estão situados entre a estação dos enfermeiros e o posto de cuidados, sendo que essa localização visa a permitir uma vigilância regular.

Esse serviço tem duas referências preponderantes: a psicoterapia institucional (Paumelle, 1999) e a Psiquiatria de setor (Fourquet \& Murard, 1980), a cargo do chefe do serviço. A respeito do uso da força, uma referência cardeal da psicoterapia institucional é o trabalho de Paumelle (1999), que descreve a diminuição da "agitação" das internas, principalmente a partir 
do momento em que elas não ficam mais permanentemente "entravadas". Essas constituem mais globalmente o quadro legítimo das práticas, no seio desse serviço, além da diversidade dos percursos e das afinidades teóricas dos médicos, psicólogos e cuidadores. Essas concepções não se correspondem inteiramente e até entram em conflito, no que se refere ao centro de gravidade do lugar do cuidado (a instituição para a Psiquiatria institucional, a "cidade" para a Psiquiatria de setor), mas elas concordam em sua crítica à instituição manicomial (pelo fato de que ela torna os pacientes incapazes e dependentes, por seu efeito "cronicizante". E por ser um lugar fechado que torna possíveis os maus-tratos). É na linha da psicoterapia institucional que a Psiquiatria de setor considera que os pacientes devem ser considerados como sujeitos e cidadãos plenos.

O enfermeiro chefe da Equipe de Acolhimento e de Crise (EAC), Julien N., tem um discurso muito paradigmático da concepção desse serviço:

Então, nós, todo o nosso trabalho consiste em considerar que [o paciente] é sujeito, portanto, que efetivamente ele sofre de algum distúrbio, que algo não está bem com ele, mas bom, ele não consegue expressar isso para nós e nós vamos tentar respeitar isso. Vamos tentar respeitar o que ele nos diz, seu sofrimento, e vamos tentar dizer a ele: "é o seguinte: vamos fazer um contrato para dialogarmos juntos, para tentar ajudá-lo sem o colocar na pele de um louco". E, além disso, tentamos tranquilizar a família. E, muitas vezes, chegamos a um justo acordo que faz com que, se estivermos muito presentes, se são as mesmas pessoas que atendem o paciente e a família, durante um período muito próximo, podemos cuidar do tratamento. Mas há situaçóes em que não tem jeito. Mas, enquanto pudermos, o acolhimento, especialmente o trabalho de crise, é realmente um trabalho alternativo à internação (Julien N., enfermeiro chefe da EAC Equipe de Acolhimento e de Crise).

A Equipe de Acolhimento e de Crise foi criada com o objetivo explícito de evitar, tanto quanto possível, as internações, de "aplacar a crise", eventualmente por encontros em ritmo sustentado, para avaliar se a internação é necessária ou não, para criar um laço com o paciente, uma "relação de confiança", ou seja, em todo caso, evitar, tanto quanto possível, o uso da restrição. O centro de gravidade da descrição das práticas é essa relação com o paciente-sujeito, e a restrição é deixada em segundo plano ("Mas há situações em que não tem jeito").

Nesse serviço, podemos notar uma desconfiança com relação à restrição em geral, em graus: em primeiro lugar, uma desconfiança latente com relação 
à internação e aos medicamentos. Isso ocorre paralelamente ao uso de um dos dois, completamente integradoàs práticas; em segundo lugar, uma desconfiança mais acentuada com relação ao quarto de isolamento, paralelamente ao uso quase diário, por um ou vários pacientes, ora do quarto de isolamento em si, ora de "tempo em quarto fechado" (por exemplo, duas horas pela manhã e, ou, à tarde, ou pontualmente, em resposta a uma "agitação"); e, em terceiro lugar, a recusa em usar as "contençōes" em geral, ou seja, faixas para amarrar o paciente na cama, o que acontece, apesar de tudo, mesmo que muito raramente. Eu pude recensear três usos de faixas durante os últimos três anos no serviço, por meio de diferentes exemplos que me foram dados, nas entrevistas, sendo que um deles aconteceu durante minha pesquisa de campo.

O mesmo enfermeiro chefe descreve o que seria o mau uso da restrição:

E o problema é que muitas vezes isso acaba assim: a gente trata os sintomas, acaba com eles, faz a contenção necessária, contenção pelas paredes ou outra coisa, pela quimioterapia, e, com isso, a gente não consegue mais trabalhar com a crise. Por exemplo, o que é que faz com que esse paciente, em determinado momento, fica agitado, não está bem, fica se debatendo na maca? (Julien, enfermeiro chefe).

O enfermeiro chefe contesta a intervenção que só leva à supressão dos sintomas, pleiteando uma compreensão do que eles significam, o que the permitiria "trabalhar com a crise". Nesse efeito de supressão daquilo que é excessivo (os sintomas), podemos ver que a internação é colocada como equivalente aos tratamentos medicamentosos, cujo efeito terapêutico é igualmente negado. No entanto, o enfermeiro não se opõe ao uso diário da internação e dos tratamentos no serviço. $\mathrm{O}$ que ele descreve aqui é um dos polos perigosos dessas práticas, o risco do uso da restrição, o momento em que o recurso a essas diferentes modalidades se torna um mau uso.

Por oposição a essas más práticas, identificaremos diferentes modos de legitimação e de usos da restrição.

\section{Modos de legitimação do recurso ao quarto de isolamento}

O recurso ao quarto de isolamento é legitimado por vários motivos, muitas vezes intricados. Do ponto de vista analítico, podemos distinguir: 1) os motivos terapêuticos mais legítimos, que visam ao bem do paciente (contenção, colocação em um lugar favorável ao cuidado, afastamento das fontes de perturbação); 2) os motivos de segurança (proteger os outros pacientes e os cuidadores da violência efetiva ou temida, por parte do paciente); 3) os 
motivos de "ordem", ligados ao bom funcionamento do serviço. Por outro lado, o motivo "punitivo", como sanção de uma transgressão, é considerado um motivo ruim, reprovável. Vamos precisar esses motivos e os tipos de situações que podem levar à colocação em quarto fechado, mostrando as tensões que interferem na mobilização desses motivos. Nem todos apresentam o mesmo grau de legitimidade, os menos legítimos tendem a ser associados ou "escondidos" debaixo dos motivos mais legítimos.

\section{Terapêutica: conter}

O papel mais terapêutico do quarto fechado é indicado pelo uso dos verbos "conter" e "enquadrar". As "paredes" podem, assim, ajudar a "conter" um paciente. Esse verbo não significa simplesmente manter um paciente em um espaço delimitado e fechado, cortando seus movimentos externamente. No mínimo, essa restrição externa, que não é diretamente terapêutica, pode ser considerada como um meio que permite a administração dos cuidados necessários ao restabelecimento do paciente. No máximo, ela permitiria ao paciente recobrar sua capacidade de se portar, além de sua capacidade de julgamento. Para um paciente percebido como "estourado", "disperso" ou simplesmente "agitado", estar em quarto fechado, ser "contido" entre quatro paredes, deveria ajudá-lo a "recompor-se" e a "tranquilizar-se", ou seja, encontrar-se e se acalmar. De fato, alguns pacientes dormem durante esse tempo de quarto fechado e saem de lá mais serenos.

Note-se que os termos "estourado" e "disperso" são usados para qualificar estados sintomáticos de psicose; "agitado" é um termo mais geral. Pode ser que se trate de uma pessoa que vai e volta ao serviço, multiplica suas demandas, solicita pacientes e cuidadores, não para de passar de um assunto ao outro, de uma emoção a outra, ou passa rapidamente a um nível de emoção intenso, seja ele tristeza, alegria ou raiva.

Do "conter" à "contenção", poderia haver somente um passo. De fato, a associação é feita espontaneamente, e "contenção" realmente é o substantivo associado ao verbo conter. No entanto, eu escutei uma psiquiatra sênior "chamar a atenção", sem dureza, de uma psiquiatra estrangeira que estava ali como interna, e que havia anotado no prontuário de um paciente a indicação de "contenção" (essa estrangeira deveria prestar um exame para que seu diploma fosse plenamente reconhecido). A psiquiatra sênior a lembrava que o termo "contenção" fazia referência às faixas e que ela tinha que escrever "quarto de isolamento". Nessa observação, encontra-se todo o trabalho de distinção entre a restrição usada no serviço, à qual se atribui um papel terapêutico, ou 
pelo menos benéfico (o quarto de isolamento), e a restrição recusada e até mesmo rejeitada, por ser considerada um cuidado ruim, ou até mesmo maus tratos (a "contenção"):

A contenção e o isolamento não são cuidados como os outros. Não se pode banalizá-los. A contenção pelas faixas, sou prudente quanto a elas. O isolamento, o quarto de isolamento, é "continente". Pode ajudar. Não é a mesma coisa do que o isolamento sensorial, que é potencialmente negativo (Pierre, chefe de serviço - anotações de uma reunião excepcional, após a agressão de uma cuidadora por uma paciente).

O duplo sentido de "conter" entre "trancar" e "recompor" fica, assim, repartido entre o verbo e o substantivo: enquanto "conter", associado a "recompor" permite trabalhar o papel do fechamento em um sentido terapêutico de cuidado, a restrição ruim é rejeitada para o lado da "contenção", que, nesse serviço, é sinônimo de faixas. É possível encontrar a mesma distinção em outros serviços, sem que ela seja carregada da mesma oposição normativa nos serviços que usam mais facilmente as faixas. $\mathrm{Na}$ literatura psiquiátrica, a noção de "contenção" pode ser associada ao uso dessas faixas.

\section{Segurança: prevenção à violência}

Os motivos de segurança podem ser enunciados separadamente e permanecer legítimos: um paciente claramente ameaçador ou que chegou às vias de fato, no serviço, poderá ser colocado no quarto de isolamento, sem que isso seja objeto de crítica ou de pedidos de explicação mais amplos; isso se aplica também para quem chega para internação de ofício, após uma história de agressão, pelo menos para fins de observação.

\section{Associação dos motivos terapêutico-segurança: ser um perigo para si e para os outros}

Os motivos de segurança são, no entanto, muitas vezes associados aos motivos terapêuticos. A continuidade desses dois tipos de motivos é marcante na expressão "ser um perigo para si ou para os outros", frequentemente encontrada na literatura e nos discursos, como justificativa para internaçôes sem consentimento, assim como para o quarto de isolamento. Nessas expressóes, o fechamento (no hospital ou no quarto de isolamento) é definido como uma proteção, com uma indeterminação, e até mesmo como uma continuidade estabelecida para aqueles a quem essa medida deve, teoricamente, proteger. 
Trata-se de uma medida a favor do paciente? Nesse caso, permanecemos com o motivo terapêutico, pelo menos visando ao bem da pessoa internada. Ou será que se trata de uma medida a favor das pessoas que convivem com ela? Nesse caso, trata-se antes de uma medida de ordem ou de segurança. Associando as duas ou deixando o objeto da proteção indeterminado, autorizamo-nos a não decidir entre esses dois motivos, nem esclarecer o motivo principal.

Alguns argumentos justificam essa associação: a pessoa pode estar tão alterada, que não se sabe se ela vai acabar agredindo alguém ou se machucando, sendo os dois casos possíveis em curto prazo. Ela pode estar tão inconsciente dos resultados de seus atos, que pode se colocar em perigo e também colocar os outros em perigo por imprudência. Enfim, um laço mais substancial é estabelecido, caso haja, no risco de uma passagem ao ato "heteroagressivo" (violência contra outra pessoa), algum sintoma, o próprio sinal do agravamento do estado, que indica a necessidade dos cuidados. Pode, portanto, haver um temor, em determinadas situações, desses dois tipos de perigo: o perigo de machucar a si próprio ou de machucar outra pessoa.

No entanto, existe uma série de casos em que esses perigos se apresentam de maneira distinta: por exemplo, ninguém chega a pensar que a pessoa possa vir a agredir alguém, mas há o temor de que ela atente contra sua vida. $\mathrm{Ou}$ ainda, sem temer uma tentativa de suicídio, teme-se que ela salte pela janela, acreditando poder voar, ou que pegue o carro sem estar em condições de dirigir, ou que atravesse a rua sem olhar. Inversamente, existem outros casos em que se pensa que a pessoa saberá preservar-se, mas cujos atos violentos anteriores e ameaças apontam para sua violência.

O fato de manter uma confusão de motivos tem, como contrapartida, não esclarecer do que se trata, nem o sentido da medida: o risco de contradição normativa na aplicação de uma restrição que não teria por sentido principal o cuidado ao paciente fica, assim, afastado.

Pudemos isolar situações nas quais os motivos terapêuticos e de segurança foram os únicos motivos declarados, mas é mais difícil isolar situações em que a justificativa pela manutenção da ordem se apresenta isoladamente.

\section{Terapêutica e manutenção da ordem}

No meio do caminho entre a terapêutica e a manutenção da ordem, seguindo uma linha pedagógico-educativa, encontramos a noção de "enquadramento", amplamente empregada no serviço: "enquadrar" significa, ao mesmo tempo, restituir o contexto do hospital, defini-lo como um lugar de cuidados e 
um lugar de vida coletivo, e lembrar as regras desse lugar, colocar limites às demandas e às ações. Isso também remete ao fato de colocar/lembrar proibições. A indicação disso está colocada na linha terapêutica, quando se trata de limitar a "onipotência" do paciente, ou seja, não só seu sentimento de ser capaz de fazer tudo, mas também seu sentimento de ter o direito de fazer tudo, de que seu desejo é a lei, de que ele pode, legitimamente, fazer impunemente o que quiser. Esse sentimento é então compreendido como um sintoma, por exemplo, de um estado maníaco.

Somos identificados como flexíveis, até mesmo permissivos. Usamos o quarto de isolamento o mínimo possível, e eles não ficam presos. É uma escolha. É mais fácil negociar quando eles não estão presos. Mas você tem razão, a negociação com um paciente em estado maníaco não serve para nada, só atrapalha. É bom que você diga isso, estamos sempre entre duas posições, uma posição humanista, de redução das restrições, mas também não vamos cair nos "bons sentimentos e no masoquismo" (Pierre, chefe de serviço).

Eu acho que há uma demanda, tipo "segure-me", que é enquadrante, é estruturante. E temos que levar em conta a periculosidade da situação. Temos que nos proteger, que pensar na segurança dos cuidadores [...] (Eric, enfermeiro).

Precisamos ser claros com relação ao que se pode negociar e ao que não se pode negociar, é preciso enquadrar as coisas. Há pequenas negociações possíveis, como com o cigarro, por exemplo (Sophia, psiquiatra - anotações durante uma reunião de síntese semanal, relativa a três pacientes internados, com os quais houve alguma dificuldade, recentemente).

A conversa, por iniciativa de um enfermeiro (Eric), diz respeito a três pacientes que deram trabalho, nos dias anteriores à reunião. Está sendo discutido, notadamente, o fato de ter havido hesitação, com relação ao uso do quarto de isolamento, ou da continuidade do uso desse quarto. O "é" em "é enquadrante" refere-se, ao mesmo tempo, a dizer "pare" ou dizer "não", bem como a usar o quarto de isolamento, conforme o caso. A "negociação" é valorizada no serviço, pois o fato de dirigir-se aos pacientes, de falar com eles, permite não somente estabelecer com eles uma boa relação, mas eventualmente resolver situações de tensão, situações nas quais, reconhecidamente, a conversa não é eficaz. Seria esse o limite de possibilidade de tratamento do paciente como um sujeito? Se a "negociação" deve cessar, os cuidadores destacam a importância de fazer com que a restrição seja acompanhada de palavras. 
Vemos aqui a associação de dois polos de motivos para o recurso ao quarto de isolamento: o polo do cuidado, com o caráter "enquadrante/estruturante" do quarto fechado; e a necessidade de garantir o bom funcionamento do serviço, assim como, nesse exemplo, a segurança dos cuidadores. Além disso, haveria a neutralização da restrição representada pelo quarto fechado, uma vez que ele é apresentado como resposta a uma demanda não formulada pelo paciente, mas manifestada por seus atos.

Aqui podemos notar também a ausência de descontinuidade entre os diferentes motivos. No trecho anterior, dois tipos de motivos são distintos, no sentido em que são enunciados separadamente ("é enquadrante, é estruturante. E temos que levar em conta a periculosidade da situação. Temos que nos proteger, que pensar na segurança dos cuidadores"), mas são justapostos e têm a função de se reforçarem mutuamente na conclusão para a qual convergem.

\section{A "agitação": sintoma, desordem ou ameaça?}

Apesar de estarem muitas vezes associados, como dizíamos, a um polo terapêutico, ou, pelo menos, "benéfico", os motivos mais distintamente relativos ao polo da ordem são identificáveis. Assim, os cuidadores poderão justificar o uso do quarto fechado pelo fato de que um paciente "dá mais trabalho", ou seja, por causa de sua "agitação", seja ela uma excitação alegre, solicitaçóes frequentes, $e, o u$, agressividade e ameaças. Além disso, o paciente irrita os outros pacientes, que se excitam, preocupam-se, angustiam-se, irritamse, solicitam, etc. A noção de "agitação" é uma noção particularmente vaga, que tende a designar condutas agressivas ou violentas, mas que pode englobar estados alegres ou simplesmente de atividade exuberante. Evidentemente, a associação implícita com a violência ou com a agressividade orienta a interpretação, no sentido de uma conduta da qual é preciso e é possível se proteger legitimamente. Mas, para além ou ao lado do temor de um gesto violento, o quarto fechado atua para regular as tensões dentro do serviço, as quais provocam o cansaço e a impaciência dos cuidadores ou potencializa seus temores. Essa divisão do recurso à restrição, menos legítima a seus olhos, aparece, notadamente, quando se fala das condiçôes do cuidado como elemento explicativo do recurso ao quarto fechado. $\mathrm{O}$ fato de falar das condições do cuidado faz emergir a dimensão contextual da percepção do risco.

\section{$10 \mathrm{O}$ contexto do cuidado}

Muitos são os cuidadores e médicos que fazem referência a transformações contextuais gerais e que tendem a incitar o recurso à restrição: evidentemente, 
a maioria dos pacientes está em internação livre, mas os períodos de estada são mais curtos e a internação acolhe as pessoas geralmente nas fases mais agudas de seus distúrbios, ou seja, no momento em que elas tendem a estar mais "agitadas"; falta pessoal aos serviços, enfermeiros e auxiliares, e estes são mais jovens, ou seja, têm uma experiência mínima e nenhuma formação psiquiátrica específica, o que pode induzir a uma menor desconfiança com relação à restrição e um maior temor das situações difíceis. A feminização das equipes é igualmente um elemento citado como atenuante do temor da relação de força física; restriçôes materiais trariam certa tranquilidade. Além disso, os serviços sofrem pressões administrativas para se equiparem com quartos de isolamento e prevenirem melhor as "fugas" de pacientes (isso ocorreu antes mesmo e independentemente das posiçôes recentes do atual presidente da República e ex-ministro do Interior). Esses elementos externos mostram a parte ligada ao contexto da acolhida do paciente e da subjetividade dos cuidadores nessas decisões, teoricamente ligadas ao estado do paciente. É preciso destacar que, se a questão da potencial periculosidade de um paciente vem à tona, ela o faz pela percepção que os cuidadores têm dele, pelo seu medo, mas também pelo sentimento de poder, diante dessa eventual periculosidade (estar em número suficiente em determinado lugar, por exemplo); por outro lado, o uso da restrição não se reduz a esses casos. Ele deve, em sua dimensão contextual, ser relacionado a determinado nível de nervosismo, de ruídos, de solicitações, de número de tarefas a serem cumpridas. Tudo isso vai influir na disponibilidade dos profissionais, em sua disposição e capacidade para, em determinado momento, acalmarem um paciente, dedicando-lhe tempo, ou, ao contrário, levá-los a buscar soluções simples para facilitar o desenrolar o trabalho no serviço.

\section{Conter, enquadrar ou punir?}

O serviço reconhece pontualmente o bom uso das restrições e admite determinados usos mais ambíguos, mas a punição faz tipicamente parte do mau uso identificado da restrição. Exceção que "confirma a regra", é sob a forma de piada que o chefe de serviço identifica, excepcionalmente, o uso punitivo legítimo do quarto fechado, a respeito de um paciente que há muito tempo reside no serviço; o termo de "punição" é então associado ao campo léxico educativo. Eric, enfermeiro, diz:

Michaël ameaçou Anna e Clarisse (duas enfermeiras). E Pierre, chefe de serviço, observa: "É preciso colocá-lo no quarto de 
isolamento, é uma das raras indicações como punição [...] é um grande doente, mas é também um chato de galocha maleducado" (Anotações de uma reunião).

Fora essa semipiada, a punição não constitui um motivo legítimo. Quando de uma reunião excepcional, a respeito da agressão violenta recente de uma paciente a uma cuidadora, a noção de punição jamais é pronunciada a respeito da paciente, mas está latente na conversa. Eu interpreto esse elemento como forte indício de ilegitimidade da noção, em contexto de cuidado. Uma parte da discussão, conduzida pelo chefe superior de saúde, coloca em paralelo a cuidadora agredida (Corine), a quem o chefe do serviço e a responsável pelo serviço de internação pediram para não voltar imediatamente para o serviço e permanecer em licença médica, e a paciente (Marie) que a agrediu. Esta ficou muito pouco tempo em quarto de isolamento e não foi para a Unidade para Pacientes Difíceis (UPD). Pelo raciocínio do chefe superior, a cuidadora está sendo punida por essa escolha, sendo obrigada a não voltar.

O que eu não entendo é o motivo pelo qual a Corine deve ir ao médico do setor, antes de retomar seu trabalho, pois não se trata de um erro, trata-se de uma falta de destreza (por parte de Corine ou por parte do médico do setor?). Em caso de licença médica, se estivermos bem, retomamos o trabalho sem voltar ao médico. Se o caso fosse com o Sr. Tilim (um outro paciente), ele teria ido para a UPD, no ato. Os pacientes que precisam ir para o quarto de isolamento o suportam muito bem (Guillaume, chefe superior de saúde: anotaçôes de uma reunião excepcional, após a agressão de uma cuidadora por uma paciente).

A psiquiatra responsável pelo serviço de internação (Sylvie) opõe a ele um raciocínio terapêutico, através do qual ela sustenta que o estado da paciente não justificava sua permanência no quarto fechado:

Sylvie:

Você está dizendo, Guillaume, que abrimos muito cedo o quarto de isolamento? Para mim, o quarto de isolamento era uma evidência no primeiro dia. Mas Marie (a paciente) reconheceu imediatamente o que aconteceu: "Façam alguma coisa por mim, me coloquem para dormir, não é normal, eu estou violenta demais, eu bati nas pessoas no metrô". Não é o caso do Sr. Tilim, e, isso, você não pode deixar de levar em conta. 
Guillaume:

Ela poderia ter ido para a UPD ou para outro serviço. Conversamos sobre isso. Porque quando há um perseguidor designado, é o paciente que muda de serviço. É preciso que a Corine volte a trabalhar.

Sylvie:

O que eu pensei clinicamente é que ela (Corine, a enfermeira) foi a perseguidora designada, em um momento agudo. Não vamos apressar as coisas. Um delírio demora seis meses para passar.

O chefe superior de saúde está tentando se situar aqui, no âmbito da defesa dos direitos dos cuidadores como profissionais: o direito que a enfermeira agredida tem de dispor de condiçôes de trabalho aceitáveis, ou seja, a transferência do serviço da paciente que a agrediu. No entanto, ele havia, anteriormente, neutralizado a noção de punição, em seu discurso, e explicado que ele próprio se situava como cuidador em relação à paciente:

Guillaume:

A questão não é a da responsabilidade, não é esse o nosso trabalho, é a do cuidado, do bom cuidado que oferecemos ao paciente. A questão não é "Ela cometeu um erro, ela tem que pagar".

A conversa marca a ambivalência do uso do quarto de isolamento (tendo como continuidade a transferência para a Unidade para Pacientes Difíceis). O chefe de serviço, no primeiro trecho citado dessa reunião, o identificava como cuidado, apesar de peculiar ("A contenção e o isolamento não são cuidados iguais aos outros"). Vemos que sua manutenção no registro do "bom cuidado" é difícil, e que pode ser fácil escorregar para outros usos (restabelecimento da calma no serviço, punição de uma transgressão). Vemos também que as normas próprias do serviço podem fazer um papel de escudo, no recurso ao quarto de isolamento (a paciente que agrediu uma cuidadora só fica ali durante o tempo julgado adaptado a seu estado), mas que diferentes registros de "o que é bom" podem entrar em conflito, em casos peculiares. Há, notadamente, um conflito entre o "bom" que é considerar o paciente como sujeito, pois isso implica que seus atos fazem sentido, e o fato de situar-se no "bom cuidado", o que implicaria suspender a questão da "responsabilidade" com relação a seus atos. 


\section{Adestramento ou condiçóes de acesso ao cuidado?}

Como vimos no início deste texto, uma das dificuldades da restrição, como destacava o enfermeiro chefe do setor, é que ela pode ter como efeito, buscado ou não, de simplesmente suspender os distúrbios e, com isso, não mais buscar o sentido dos atos do paciente, e até mesmo impedir que ele seja percebido. Outro enfermeiro vai mais longe, temendo que a restrição tenha o efeito de "domesticar", "dominar", "adestrar" o paciente indócil:

No fim das contas, foi preciso colocar (esse paciente) em um quarto, afastado, fechado, com hora certa de abertura, para, de algum modo, domesticá-lo. Chega um determinado momento em que abrimos a porta, e a pessoa já não tem mais vontade de correr dali. Então, isso é bom ou não (risos), podemos pensar de diferentes maneiras [...].

Em que consistiriam os dois argumentos? Eric responde:

Bem, para mim, eles, muitas vezes, são de ordem filosófica. $\mathrm{O}$ que fizemos é que acabamos dominando alguém, adestrando-o. Será que, no fim das contas, nos sentimos bem com isso? O outro aspecto é: vamos deixar as armas de lado por um tempo, para podermos ir a outro campo, falar um pouquinho mais dele e ajudá-lo da melhor maneira, para que ele possa ter uma vida mais agradável, um pouco mais confortável. Porque, querendo ou não, o objetivo aqui é este, que ele fique internado durante o período mais curto possível, e permitir que as pessoas vivam do lado de fora com sua patologia, porque raramente alguém se cura, e viver da melhor maneira (Eric, enfermeiro, em uma entrevista).

O objetivo do enfermeiro, aqui, não é jogar o paciente na animalidade, mas ele critica a conduta dos cuidadores, em sua percepção do paciente, e no que eles fazem com ele, com o risco de ele perder algo de si próprio, ao submeter-se aos cuidados. Isso perturba a realização dos cuidados posteriores à restrição: não seria ela então uma forma de violência moral? No entanto, ele logo propõe uma interpretação paralela, na qual a restrição poderia permitir o acesso ao cuidado, saindo da relação de força (não pelo equilíbrio, mas pela assimetria que o paciente sentiu) para permitir que a pessoa "viva da melhor maneira" com uma "patologia de longo prazo". A presença quase simultânea dessas duas interpretaçôes marca o distúrbio que cerca a restrição no cuidado. 


\section{Conclusão}

Além da crítica aos comportamentos brutais e humilhantes, o uso da restrição ou da força é enquadrado em uma definição de seus usos legítimos e ilegítimos: um uso terapêutico, não só como condição temporária de entrada no cuidado, mas como dispositivo continente, protetor e tranquilizador para o paciente; um uso de segurança, contra pacientes violentos, que também é legítimo. Usos ligados ao bom funcionamento do serviço são geralmente associados ou justificados como um desses motivos anteriores; o uso punitivo é unanimemente condenado. A restrição/força permanece sendo, para os cuidadores, objeto de uma vigilante crítica, atenta aos abusos, tais como: o recurso ao quarto fechado ou outras coerções que "facilitam as coisas", o que seria uma resposta punitiva a condutas que perturbam o serviço. A presença de normas ligadas à crítica manicomial continua a servir de escudo. Além disso, todo um conjunto de dispositivos práticos é aplicado a fim de evitar o confronto violento ou a percepção de uma restrição abusiva. Os dispositivos de palavras, de negociação, são desenvolvidos de maneira a fazer com que a pessoa se conforme ao que se espera dela, ao que é julgado bom para ela, o que inclui uma atenção a suas demandas. Mas até mesmo nas situações em que não há emprego de força, a questão da legitimidade da coerção é colocada de modo latente, nesse vaivém de motivos. Nessa economia de relação de forças e da autoridade médica, parece que o uso da coerção permanece ambíguo, e sua articulação ao cuidado, problemática. Essa ambiguidade joga certa sombra até mesmo no consentimento do paciente ao cuidado.

\section{Referências}

Agence Nationale d'Accréditation et d'Evaluation en Santé. (1998). L'évaluation des pratiques professionnelles dans les établissements de santé: l'audit clinique appliqué à l'utilisation des chambres d'isolement en psychiatrie. Paris: ANAES.

Aristóteles. (1990). Ética a Nicômaco. (v. 3). Paris: Vrin.

Bourdieu, P. \& Passeron, J.-C. (1970). La reproduction: éléments pour une théorie du système d'enseignement. Paris: Minuit.

Castel, R. (1986). La construction des significations et le désert du sens. Sciences Sociales et Santé, 4 (2), 33-38.

Fourquet, F. \& Murard, L. (1980). Histoire de la psychiatrie de secteur. Paris: Recherches. 
Goffman, E. (1979). Asiles. Paris: Minuit.

Lovell, A. M. (1996). Coertion and social control: a framework for research on agressive strategies in community mental health. In: D. L. Dennis \& J. Monahan (ed.). Coertion and aggressive treatment: a new frontier in mental health law. (p.252-264). New York: Plenum Press.

Moreau, D. (2007). Faire interner un proche? Le travail sur l'autonomie en contexte detroubles psychiques. Paris: CNAF. Dossiers d'études, $\mathrm{n}^{\circ} 94$. Disponível em: <http://www. cnaf.fr/web/WebCnaf.nsf/090ba6646193ccc8c125684f00 5898f3/f5eeebbd3bf65732c1257314003723f4/\$FILE/Dossier\%2094\%20 -\%20PRIX.doc>. Acesso em: 27 mar. 2009.

Paumelle, Ph. (1999). Essais de traitement collectif d'un quartier d'agités. Rennes: Editions ENSP.

Senon, J.-L. \& Jonas, C. (2004). Droits des patients en psychiatrie. Encyclopédie Médico-Chirurgicale, 1 (1), 107-127. 